\title{
The Effects of Differences in Post Canal Widths on Microleakage in Prefabricated Fiber Reinforced Composites
}

\author{
Ni Kadek Sugianitri \\ Department of Prosthodontics, Faculty of Dentistry, \\ Mahasaraswati University Denpasar Bali \\ Email: sugianitri@gmail.com
}

Introduction: Fiber Reinforced Composite (FRC) post is one of the choices in post root canal treatment. Resin cement polymerization results in shrinkage, creating micro gaps between the FRC posts and the root canal wall. This study aimed to find microleakage differences of prefabricated FRC posts with different root canal diameters. Methods: Twenty-four maxillary central incisors were used, the root length was $13 \mathrm{~mm}$ from the apex. The root canal was prepared with conventional technique and then filled with a single cone technique. Samples were divided into 4 treatment groups of $1.2 \mathrm{~mm}, 1.4 \mathrm{~mm}, 1.6 \mathrm{~mm}$ and 1.8 $\mathrm{mm}$ diameter, cemented, then coated with sticky wax and nail polish and immersed in $2 \%$ methylene blue liquid and put into an incubator at $37^{\circ} \mathrm{C}$ for 72 hours. Objects were divided into two mesiodistal directions, observed under a 20x-magnification stereomicroscope. Results: Kruskal-Wallis test showed significant differences in all treatment groups ( $\mathrm{p}<0.05)$. Mann-Whitney test showed differences between groups $(\mathrm{p}<0.05)$ of $\varnothing 1.2 \mathrm{~mm}$ and $\varnothing 1.6$ $\mathrm{mm}, \varnothing 1.2 \mathrm{~mm}$ and $\varnothing 1.8 \mathrm{~mm}$, and $\varnothing 1.4 \mathrm{~mm}$ and $\varnothing 1.8 \mathrm{~mm}$ group. Discussion: The main cause of microleakage at the edge of restoration is because the resin cannot completely close the edges, resulting in shrinkage and contraction during polymerization of the composite resin. Conclusion: There were microleakage in the four groups, the wider root canal might lead to greater microleakage.

Keyword: Microleakage, FRC, root canal diameters.

\section{Pendahuluan}

Usaha untuk mempertahankan gigi dalam rongga mulut dapat ditempuh dalam berbagai cara, salah satunya pada kasus kehilangan struktur gigi yang banyak akibat karies, fraktur ataupun pengambilan jaringan gigi saat melakukan akses preparasi perawatan saluran akar seringkali membutuhkan perawatan pasak. Pasak digunakan untuk meneruskan tekanan yang diterima gigi secara merata sepanjang akar gigi serta sebagai retensi intraradikular pada mahkota gigi.

Pasak dibedakan menjadi dua yaitu pasak prefabricated dan fabricated, sedangkan berdasarkan material yang digunakan, pasak terbagi atas pasak logam dan non logam. Beberapa pasak non logam yaitu pasak fiber, keramik dan Fiber reinforced polymer $(F R C) .{ }^{1}$ Keunggulan pasak $F R C$ yaitu estetis yang bagus, mampu berikatan dengan struktur gigi dan memiliki modulus elastisitas yang menyerupai dentin, kekurangannya adalah sering 
terjadinya pengerutan saat polimerisasi menyebabkan terjadinya microcracks diantara lapisan semen pelekat resin dan kebocoran mikro di sepanjang ruangan pasak ${ }^{2,3}$.

Penggunaan pasak $F R C$ juga mengurangi risiko terjadinya fraktur akar maupun perforasi akar dan mampu beradaptasi dengan berbagai bentuk saluran akar baik yang berbentuk bulat maupun oval. Penelitian ini menggunakan pasak FRC prefabricated dengan lebar saluran pasak yang berbeda untuk mengetahui seberapa besar pengaruhnya terhadap terjadinya celah mikro $^{4,5}$.

Tujuan penelitian ini adalah untuk mengetahui kebocoran mikro yang ditimbulkan pada penggunaan pasak FRC prefabricated dengan lebar diameter saluran pasak 1,2 mm, 1,4 $\mathrm{mm}, 1,6 \mathrm{~mm}$ dan 1,8 $\mathrm{mm}$ dan mengetahui perbedaan kebocoran mikro yang ditimbulkan pada penggunaan pasak $F R C$ prefabricated antara lebar saluran pasak 1,2 $\mathrm{mm}$ dengan 1,4 mm, 1,6 $\mathrm{mm}$ dan $1,8 \mathrm{~mm}$.

\section{Bahan dan Metode Penelitian}

Metode yang digunakan dalam penelitian ini adalah metode eksperimental laboratoris dengan rancangan penelitian posttest-only control group design untuk mengetahui kebocoran mikro yang ditimbulkan pada penggunaan pasak FRC prefabricated dengan lebar diameter saluran pasak yang berbeda - beda, yaitu diameter 1,2 mm, 1,4 mm, 1,6 mm dan 1,8 mm.

Objek penelitian, yaitu dengan menggunakan gigi insisivus sentral rahang atas, dengan syarat tidak terdapat kerusakan pada bagian akar gigi. Membersihkan objek penelitian dengan direndam menggunakan hidrogen peroksida 3\% selama \pm 20 menit. Melakukan pemotongan pada bagian koronal gigi sehingga didapat panjang seragam, yaitu $13 \mathrm{~mm}$ dari apikal $^{5}$.

Tahap melakukan perawatan saluran akar, semua gigi dilakukan perawatan saluran akar dengan menggunakan preparasi teknik konvensional (jarum reamer dan file sudah dipasangi stopper sesuai panjang kerja yang telah ditentukan) dengan panjang kerja $12 \mathrm{~mm}$. Jarum digunakan secara berurutan (dimulai dari nomor terkecil hingga ke besar), yaitu ukuran 15 80, setiap pergantian jarum, lakukan irigasi menggunakan $\mathrm{NaOCl}$ dan EDTA $17 \%$ secara bergantian lalu diakhiri dengan irigasi menggunakan EDTA $17 \%$. Keringkan saluran akar menggunakan paper point. Pengisian, yaitu menggunakan teknik single cone, ulasi dinding saluran akar dengan calciuim hydroxide paste menggunakan jarum lentulo, ulasi pula guttap point dengan pasta (diameter guttap point disesuaikan dengan nomor jarum reamer atau file yang terakhir digunakan dan beri tanda sesuai panjang kerja). Potong guttap point 1-2 mm 
dari batas panjang kerja dengan menggunakan ekskavator yang ujungnya telah dipanaskan di atas api bunsen kavitas ditutup menggunakan tumpatan sementara.

Tahap preparasi saluran pasak, yaitu lakukan preparasi saluran pasak pada semua objek penelitian dengan cara guttap point diambil menggunakan plugger yang dipanaskan, lalu dilanjutkan peeso reamer yang telah dipasangi stopper sepanjang $8 \mathrm{~mm}$. Guttap point yang tersisa adalah $4 \mathrm{~mm}$. Panjang pasak diperoleh dari dua pertiga panjang akar gigi yaitu $8 \mathrm{~mm}$.

Objek penelitian dibagi menjadi empat kelompok, masing - masing kelompok terdiri dari 6 buah sampel yaitu : kelompok 1: lebar preparasi saluran pasak berdiameter 1,2 mm, kelompok 2: lebar preparasi saluran pasak berdiameter 1,4 mm, kelompok 3: lebar preparasi saluran pasak berdiameter 1,6 mm, kelompok 4: lebar preparasi saluran pasak berdiameter 1,8 mm. Dilakukan preparasi saluran pasak menggunakan peeso reamer dan jarum khusus pada bahan pasak berdasarkan ukuran pasak masing - masing lalu beri tanda menggunakan stopper sesuai dengan panjang saluran pasak. Setelah itu bersihkan saluran pasak menggunakan akuades, dilanjutkan dengan EDTA 17\%, lalu keringkan menggunakan paper point.

Tahapan insersi serta penyemenan pasak adalah pelapisan permukaan akar gigi menggunakan sticky wax dan cat kuku masing - masing satu lapisan agar cairan pewarna methylene blue $2 \%$ tidak merembes masuk melalui sisi akar gigi. Setelah itu biarkan mengering diudara terbuka. Setelah kering, rendam dalam larutan methylene blue $2 \%$ lalu simpan dalam inkubator dengan suhu $37^{\circ} \mathrm{C}$ selama 72 jam. Letakan objek penelitian sesuai kelompoknya ke dalam wadah penirisan lalu siram dengan air mengalir setelah itu tiriskan selama \pm 24 jam. Setelah kering, objek penelitian dibelah menjadi 2 bagian dengan arah mesiodistal menggunakan diamond disc. ${ }^{6,7}$

Pada pengamatan celah mikro, objek penelitian diamati dengan menggunakan mikroskop stereo dengan pembesaran 20 kali. Melakukan pencatatan skor celah mikro dengan mengamati perluasan cairan methylene blue $2 \%$, Pencatatan skor celah mikro dengan mengamati perluasan cairan methylene blue $2 \%$ terlihat pada tabel 1.

\section{Tabel 1. Skor Dye Penetration}

\begin{tabular}{cl}
\hline Skor & \multicolumn{1}{c}{ Definisi } \\
\hline 0 & Tidak ada kebocoran \\
1 & Kebocoran mencapai 1/3 dinding akar \\
2 & Kebocoran mencapai 2/3 dinding akar \\
3 & Kebocoran mencapai seluruh dinding akar \\
\hline
\end{tabular}




\section{Hasil}

Pengamatan pada 24 gigi insisivus sentral rahang yang terbagi menjadi empat kelompok perlakuan yang dibedakan berdasarkan perbedaan lebar diameter saluran pasak pengukuran kebocoran mikro ditentukan dengan mengamati perluasan methylene blue $2 \%$ pada dinding akar, setelah itu ditentukan skor pada masing - masing obyek penelitian. Data hasil perhitungan kebocoran mikro yang diperoleh kemudian diolah uji normalitas dengan uji Shapiro - Wilk (tabel 2).

Tabel 2. Data Uji Normalitas pada Masing - Masing Kelompok Perlakuan

\begin{tabular}{lccc}
\hline & \multicolumn{3}{c}{ Shapiro - Wilk } \\
\cline { 2 - 4 } & Statistic & df & p \\
\hline Kel. 1 & & 6 & \\
Kel.2 & 0,496 & 6 & 0,000 \\
Kel.3 & 0,640 & 6 & 0,001 \\
Kel.4 & 0,496 & 6 & 0,000 \\
\hline
\end{tabular}

Data di atas menunjukan tidak berdistribusi normal nilai $\mathrm{p}<0,05$, maka analisis data dilanjutkan menggunakan uji statistik non parametrik. Untuk tes homogenitas tidak dilanjutkan karena data tidak memenuhi syarat uji parametrik yaitu data harus berdistribusi normal.

Uji Kruskal - Wallis untuk melihat perbedaan yang signifikan pada seluruh kelompok perlakuan, uji ini jelas digunakan untuk melihat perbandingan lebih dari dua kelompok perlakuan dengan data berbentuk ranking. Tabel 3 dibawah ini menyajikan nilai signifikasi pada seluruh kelompok perlakuan beserta ranking pada setiap kelompok perlakuan.

Tabel 3. Data Uji Signifikansi pada Seluruh Kelompok Perlakuan

\begin{tabular}{cccc}
\hline Perlakuan & N & Mean Rank & Sig. \\
$\varnothing 1,2 \mathrm{~mm}$ & 6 & 6.00 & \\
$\varnothing 1,4 \mathrm{~mm}$ & 6 & 7.33 & 0.000 \\
$\varnothing 1,6 \mathrm{~mm}$ & 6 & 16.00 & \\
$\varnothing 1,8 \mathrm{~mm}$ & 6 & 20.67 & \\
\hline
\end{tabular}


Data diatas menunjukan adanya perbedaan yang signifikan karena nilai $\mathrm{p}=0,000$ $(\mathrm{p}<0,05)$ diantara keempat kelompok perlakuan. Dimana urutan ranking terkecil hingga terbesar yaitu lebar saluran pasak berdiameter 1,2 mm, 1,4 mm, 1,6 mm dan 1,8 mm.

Selanjutnya dilakukan uji Mann - Whitney Test untuk menguji dua kelompok atau sampel dan yang mempunyai banyak kelompok atau sampel yang berbeda. Tabel 4 dibawah ini akan menyajikan nilai perbedaan signifikansi antara kelompok yang satu dengan setiap kelompok lainnya.

Tabel 4. Uji Signifikan antar Kelompok Perlakuan

\begin{tabular}{rrrrc}
\hline \multicolumn{2}{c}{$\begin{array}{c}\text { Perbandingan antar } \\
\text { Kelompok Perlakuan }\end{array}$} & $\mathrm{p}$ \\
\hline$\varnothing 1,2 \mathrm{~mm}$ & $\varnothing 1,4 \mathrm{~mm}$ & $\varnothing 1,2 \mathrm{~mm}=6.00$ & $\varnothing 1,4 \mathrm{~mm}=7.00$ & 0,317 \\
& $\varnothing 1,6 \mathrm{~mm}$ & $\varnothing 1,2 \mathrm{~mm}=3.50$ & $\varnothing 1,6 \mathrm{~mm}=9.50$ & 0,002 \\
$\varnothing 1,8 \mathrm{~mm}$ & $\varnothing 1,2 \mathrm{~mm}=3.50$ & $\varnothing 1,8 \mathrm{~mm}=9.50$ & 0,001 \\
$\varnothing 1,4 \mathrm{~mm}$ & $\varnothing 1,6 \mathrm{~mm}$ & $\varnothing 1,4 \mathrm{~mm}=3.83$ & $\varnothing 1,6 \mathrm{~mm}=9.17$ & 0,006 \\
& $\varnothing 1,8 \mathrm{~mm}$ & $\varnothing 1,4 \mathrm{~mm}=3.50$ & $\varnothing 1,8 \mathrm{~mm}=9.50$ & 0,002 \\
$\varnothing 1,6 \mathrm{~mm}$ & $\varnothing 1,8 \mathrm{~mm}$ & $\varnothing 1,6 \mathrm{~mm}=4.33$ & $\varnothing 1,8 \mathrm{~mm}=8.67$ & 0,018 \\
\hline
\end{tabular}

Dari tabel 4 diatas menunjukkan bahwa semua kelompok perlakuan memiliki perbedaan yang signifikan karena nilai $\mathrm{p}<0,05$, kecuali kelompok perlakuan $\varnothing 1,2 \mathrm{~mm}$ dengan $\emptyset 1,4 \mathrm{~mm}$ tidak memiliki perbedaan yang signifikan karena nilai $\mathrm{p}>0,05$.

\section{Pembahasan}

Pada penelitian ini dapat dilihat bahwa perbedaan ukuran diameter saluran pasak berpengaruh pada perbedaan kebocoran mikro yang ditimbulkan, preparasi saluran pasak yang lebih besar akan menimbulkan kebocoran mikro yang lebih besar dibandingkan dengan preparasi saluran pasak yang ukurannya lebih kecil, hal ini disebabkan oleh volume semen pelekat resin lebih banyak sehingga dapat meningkatkan terjadinya pengerutan pada saat polimerisasi. Kontraksi polimerisasi akan menimbulkan tegangan diantara semen perekat resin dan dentin saluran akar yang dapat menimbulkan celah mikro antara pasak dan dinding saluran $\operatorname{akar}^{7,8}$.

Skor yang didapat pada perlakuan lebar saluran pasak berdiameter 1,2 mm yaitu bernilai 1 pada keenam sampelnya. Keenam sampel tersebut bernilai konstan, karena pada 
pengamatan kebocoran mikro terlihat bahwa perluasan cairan methylene blue $2 \%$ berada hanya pada permukaan atas saja dan tidak ada yang melewati $1 / 3$ dinding akar.

A

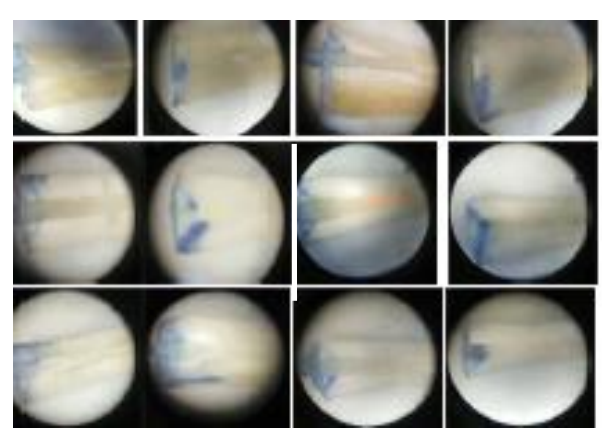

Gambar 1: Lebar saluran pasak $\emptyset$ 1,2 mm didapatkan skor kebocoran mikro 1 pada keenam saluran akar dari sisi A dan B.

A

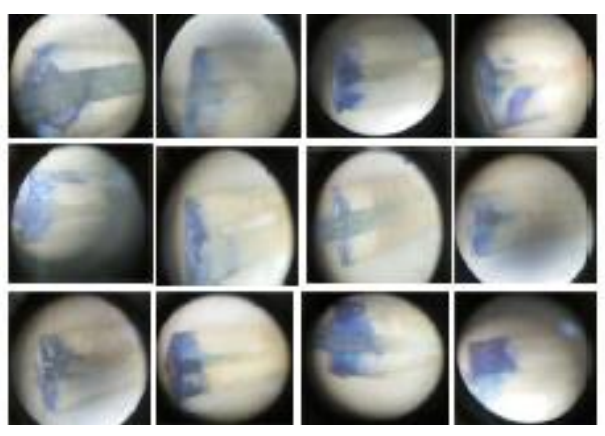

Gambar 2: Lebar $\emptyset$ 1,4 mm didapatkan skor 1 (5 sampel ), skor 2 (1 sampel) dari sisi A, dan skor 1 (6 sampel) dari sisi B

A B

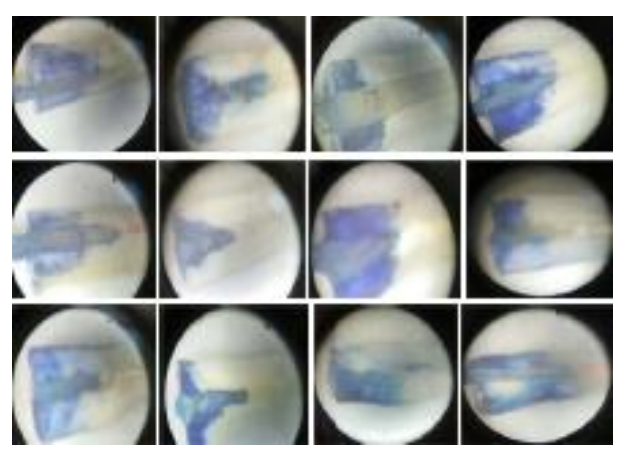

Gambar 3: Lebar $\varnothing ~ 1,6 \mathrm{~mm}$ dari sisi A skor 1 (2 sampel) skor 2 (4 sampel) dari sisi B skor 1 (2 sampel), skor 2 (4 sampel). 


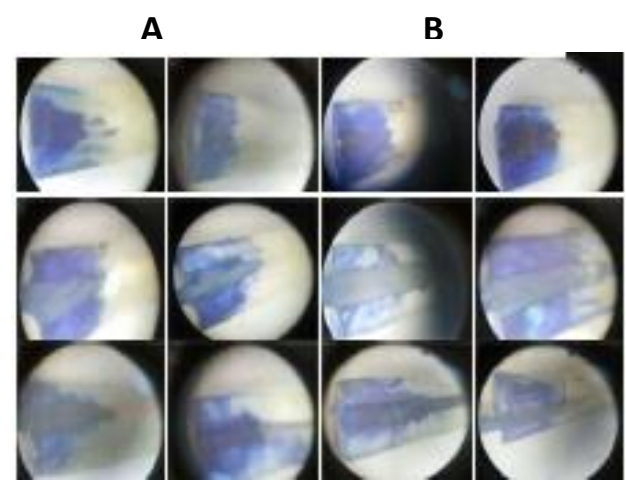

Gambar 4: Lebar Ø 1,8 mm dari sisi A skor 1 (1 sampel), skor 2 (5 sampel), skor 3 (6 sampel)

Skor yang didapat pada perlakuan lebar saluran pasak berdiameter 1,4 mm, 1,6 mm dan 1,8 mm memiliki keragaman nilai pada keenam sampelnya. Dari perluasan cairan methylene blue $2 \%$ terlihat perbedaan pada keempat kelompok perlakuan, baik dari panjang perluasan cairan methyelene blue $2 \%$ ataupun dari kepekatan warna yang dihasilkan oleh penetrasi cairan warna tersebut. Terlihat bahwa pada keempat perlakuan lebar saluran pasak memiliki panjang perluasaan dan kepekatan cairan yang berbeda yaitu semakin meningkat pada perlakuan lebar saluran pasak yang lebih besar.

Penyebab utama kebocoran mikro pada tepi restorasi yaitu karena resin tidak dapat menutup bagian tepi dengan sempurna, akibatnya terjadi penyusutan (shrinkage) dan kontraksi pada saat polimerisasi resin komposit ${ }^{9,10}$. Dalam penelitian ini dapat dilihat bahwa pada preparasi saluran pasak yang lebih besar akan menimbulkan kebocoran mikro yang lebih besar dibandingkan dengan preparasi saluran pasak yang ukurannya lebih kecil, hal ini disebabkan oleh volume semen pelekat resin lebih banyak sehingga dapat meningkatkan terjadinya pengerutan pada saat polimerisasi ${ }^{10}$. Terlihat bahwa pada keempat perlakuan lebar saluran pasak memiliki panjang perluasaan dan kepekatan cairan yang berbeda yaitu semakin meningkat pada perlakuan lebar saluran pasak yang lebih besar.

\section{Simpulan}

Berdasarkan pembahasan dan hasil penelitian yang telah dilakukan, dapat disimpulkan sebagai berikut :

1. Terdapat kebocoran mikro pada keempat kelompok lebar saluran pasak yang diteliti.

2. Semakin lebar diameter saluran pasak maka kebocoran mikro yang ditimbulkan semakin besar pula dan sebaliknya. 


\section{Daftar Pustaka}

1. Deliperi, S. Direct Fiber-reinforced composite restoration in an endodontically-treated molar. Oper Dent 2008 Mar-Apr;33(2):209-14

2. Deliperi, S., Bardwell, D.N., Coiana, C. Reconstruction of Devital Teeth Using Direct Fiber- Reinforced Composite Resins. J Adhes Dent 2005 Summer;7(2):165-71.

3. Veridiana NR, Cézar Jr SP, Maria R., et al. Bond Strength Between Fiber Posts and Composite Resin Core - Influence of Temperature on Silane Coupling Agents. Br Dent J 2012;23(1):8-14

4. Kivanc TA, Ulusoy G. Fracture resistance of thin-walled roots restored with different post systems. International Endodontic Journal 2009 Nov;42(11):997-1003.

5. Krejei, I., dan Stavridakis, M. New prespectives on dentin adhesion differing methods of bonding. Pract Periodontics Aesthet Dent 2000 Oct;12(8):727-32.

6. Schwartz, R.S., dan Robbin, J.W. Post placement and restoration of endodontically treated teeth. J Endod 2004 May;30(5):289-301.

7. Mood P.C, Tabassian M.S, Colbreath T.E. 2002, Flow Characteristics and Film Thickness of Flowable Resin Composites. Oper Dent 2002 May-Jun;27(3):248-53.

8. Mehta S B, Millar B J. A comparison of the survival of fiber posts cemented with two different composite resin systems. Br Dent J 2008 Dec 13;205(11):E23.

9. Seefeld, F., Wenz, H.Z., Ludwig, K., dan Kern, M., 2007, Resistance to fracture and structural characteristics of different fiber reinforced post system. Dent Mater 2007 Mar;23(3):265-71.

10. Bayne S.C, Thompson J.Y, Swift E.J. A Characterization of First Generation Flowable Composite. JADA Vol.129 1998 May;129(5):567-577.

11. Da Silva E.M., Dos Santos G.O., Guimaraes J.G.A., Barcellos A.A.L., Sampaio E.M. The influence of c-factor flexural modulus and viscous flow on gap formation in resin composite restorations. Oper Dent 2007 Jul-Aug;32(4):356-62 